\title{
Survey finds that restructuring has improved UK university research
}

London. The wave of closures and mergers of university science departments in Britain over the past few years has significantly increased the quality of the research being produced, according to figures released last week by the Universities Funding Council (UFC). The figures come from an assessment of the research output of every university department in the country, based primarily on a detailed study of published articles.

Some 62 panels of expert reviewers looked at the work of 43,000 academic staff from 172 institutions. Under the terms of the exercise - conducted to help the newly created Higher Education Funding Councils for England. Wales and Scotland decide how to allocate $£ 650$ million (US $\$ 1$ billion) next year for research - each department was rated on a scale of one (low) to five (high). Three years ago, the average score for all university departments across the country was 3.2 ; this year it has risen to 3.7.

Critics say that the figures are misleading and that the higher score may reflect merely an improved ability to impress a panel of outside reviewers. Although each researcher was allowed to present only two scientific papers, concern remains that the quantity of research results may still outweigh quality or that a relatively brief contribution to a well-known scientific journal may have greater impact than a more substantial contribution to a less prominent journal.

But those responsible for the assessment believe that the exercise provides clear evidence of an improvement in research output. This change, they argue, has been the result of decisions by some universities to close down departments that scored badly on previous exercises or to merge them with stronger departments.

They give as an example the high marks scored by a group of university Earthscience departments, each of which has been a focus for government support following the recommendations of the Roxburgh report in the mid-1980s. Similarly, all the university chemistry departments receiving a score of one in the 1989 exercise have since been closed or merged, boosting the overall ratings of the universities concerned.

As in the previous exercise, the Universities of Cambridge and Oxford emerged with the highest ratings. Some 40 of 52 departments at Cambridge were awarded the maximum of five points, representing work of international excellence. Oxford lagged behind, scoring top marks in 28 of 45 departments.

Other institutions that scored highly in the overall ratings included University
College, London, with 22 departments receiving highest marks; Imperial College, London, with 12 departments; and the Universities of Warwick and Nottingham, with 11. The University of Edinburgh, with 11 top-rated departments, headed the list of Scottish universities.

Several universities - in particular, Bath, Kecle, Brunel and Lancaster - showed a marked improvement in their overall scores. This reflects efforts to weed out weak spots and build up strengths. At the same time, the review panels awarded only one point to 20 "old" university departments; as a result, these are unlikely to receive any funds for research next year.

This year's exercise was the first time that the research in the so-called "new universities"- previously polytechnics or similar colleges that have recently been allowed to call themselves universities - had been assessed. Although many of these scored low marks on the ratings, 12 departments received a score of four, indicating that the work meets high national standards.

"The existence of pockets of high-quality research shows that many of these 'new' universities have done well, particularly with only limited funding to develop their research potential", says Graeme Davies of the UFC.

The Association of University Teachers, which represents academic staff in pay negotiations with the government, called the exercise an "impressive achievement" given declining government support for research. But the union warned that the results may have been influenced by the methodology used - in particular, by the freedom given to university departments to decide how many of their research staff to include in the exercise. "It is possible for two departments with identical strengths to have taken different decisions about including staff and to have been given a different - and thus flawed - rating", it said. David Dickson

\section{Reports examine US universities}

Washington. Two reports issued this week (21 December) on the health of US research universities* serve as reminders of how easy it is to propose what should be done and how hard it is to bring about substantive change.

At what may be his final press conference, D. Allan Bromley, whose tenure as assistant to the president for science and technology ends next month, expressed his pleasure at presenting the recommendations of both the President's Council of Advisors on Science and Technology (PCAST) and the Federal Coordinating Council for Science, Engineering and Technology (FCCSET) on ways in which the nation's 150 to 200 chief research universities could maintain US leadership on the frontiers of science. That feeling is not surprising, given that in 1986 he and industrialist David Packard, as members of PCAST's predecessor, the White House Science Council. produced a report containing some of the same recommendations, including full reimbursement for the cost of federally funded research and an end to congressional earmarking of research funds awarded without scientific review.

The 46-page PCAST report makes a point of saying that universities must weed out those research programmes not of worldclass quality because the US government can no longer afford to support an everexpanding academic research enterprise. And it tells government agencies not to create programmes "that would increase the net capacity of the system". Yet it calls for a "substantial" federal programme to repair and renovate ageing academic research facilities and a new federal programme of undergraduate scholarships. The facilities programme, long opposed by the Bush administration, could easily cost hundreds of millions of dollars annually and the scholarships, if successful, would eventually increase the number of academic scientists and, thus, the demands for funding from the federal government.

Harold Shapiro, president of Princeton University and vice chairman of PCAST. said that the report asks research universities "to put quality ahead of quantity and scope", reversing a trend since the 1960 s of aspiring to greatness in an increasing number of fields. Such a policy also flies in the face of a programme begun by the National Science Foundation and now spreading to half a dozen research agencies that helps have-not states to do better in national competitions for federal dollars. "I don't think it's wise to increase the base when you can't adequately support what already exists", said Shapiro, who added that universities must decide for themselves what departments to trim or eliminate.

Jeffrey Mervis

* The PCAST report is Renewing The Promise: Research-Intensive Universities and the Nation; the FCCSET report is In the National Interest: The Federal Government and Research-Intensive Universities. 